\title{
Variations on the Theme of Information Literacy - Implementation of Information Literacy into the First-Year Curriculum at Åbo Akademi University
}

\author{
Eva Costiander-Huldén ${ }^{1}{ }^{*}$, Linda Nisula ${ }^{1}$ and Anna Sundberg ${ }^{2}$ \\ ${ }^{1}$ Åbo Akademi University Library, ${ }^{2}$ Åbo Akademi University
}

\begin{abstract}
How can information literacy (IL) courses be organized into the curriculum in the best possible way for first-year students at Finnish universities? This question has been discussed time and time again. At Åbo Akademi University we have, since fall 2015, developed a course in Academic study skills where IL is included in the course. This means that IL is now for the first time included in all study programmes at the university. The IL module is, however, implemented in different ways in different faculties. In this article, we will focus on the method of embedded learning of IL in the study programme of Chemical Engineering, as it was implemented during the fall semester 2015 for all freshmen. For the first time the library was involved in a "hands-on" project with practical tasks at the Faculty of Science and Engineering. The students were motivated to learn how to search for information and how to improve their skills in reference management, and they passed the course.
\end{abstract}

Keywords: embedded librarianship, academic study skills, information literacy, first-year experience

\footnotetext{
*Contact:

Eva Costiander-Huldén, M.A., Information specialist

Åbo Akademi University Library

E-mail: ecostian@abo.fi
} 


\section{Introduction}

Since the 1990s Åbo Akademi University Library ( $\AA$ AUL) has offered general introductions to our library services and resources for our first-year students. The introductions have included demonstrations of the library database and the portal for electronic resources. Some of the university programmes have also included short courses in information search and retrieval in their curriculum. The library has also offered optional web-based introduction courses for beginners. These optional, web-based introductions were offered from 2007 to 2014. A presentation of these courses was held at the Creating Knowledge Conference in Turku/Åbo in 2008, where the added value of web-based teaching and learning were presented (CostianderHuldén \& Forslund, 2008).

For many years we have felt the need to develop courses in the context of academic study skills in collaboration with the faculties/teachers. Such courses would be tailor-made for the different study programmes. Finally, in 2014, the university teachers, study advisors and information specialists, in co-operation with the Educations services at the university, developed eight different courses, called Academic study skills (Akademiska studiefärdigheter, ASF). Each course provides five European Credit Transfer System (ECTS) credits. The courses covered study orientation, study techniques, information literacy, and study planning. The courses were implemented in different ways in the curricula. Some courses were taught as separate modules. Some were embedded in a project with a joint goal, for example, to produce a poster and/or a report on a theme or problem, as in the case of the subject Chemical engineering. Here all the aspects of study skills was taken into consideration simultaneously.

\section{Learning outcomes and methods for information literacy within an Academic study skills course}

In the Academic study skills course, the ÅAUL was responsible for the information literacy part. Learning outcomes are always crucial in the planning of academic courses, and the learning activities and the examination should be constructively linked to the learning outcomes of the courses and education programmes (Elmgren \& Henriksson, 2013, p. 139). The learning outcomes of the IL part of the course were also determined by the national recommendations of information literacy (Rekommendation för högskolorna i Finland - Informationskompetens i högskolestiderna, 2013).

The common learning outcomes were:

- Students are expected to, independently, after the course:

- be able to use relevant information resources and library services effectively

- construct search terms and use different search strategies

- assess the material's reliability and quality (source criticism) as well as the ethical guidelines for the use of materials

- know the principles of reference management

During the planning sessions of the IL part, the following different approaches to the learning and teaching methods were observed:

\section{Faculty of Arts, Psychology and Theology}

At the Faculty of Arts, Psychology and Theology all 180 freshmen were from the very beginning of the ASF course divided into 20 mixed groups. One of the goals of this mixture was to strengthen the unity of the faculty students and staff. The groups had 5 meetings, and 14 assignments, of which some were individual. The assignments included self-reflection about ones studies, interviews with group supervisors about academic careers, learning styles and strategies, a time-thieves test, and getting acquainted with the study-planning tool MinPlan. Most of the assignments and the instructions were in the learning platform Moodle. As for the IL 
part of the course, the groups were re-organized into five groups according to their subjects: theology, language studies, psychology and logopedics, and two groups within culture studies. In the IL modules, the students were supposed to acquaint themselves with the study material (videos, power points and web texts) before they undertook the assignments. The assignments demanded that the students would search in databases relevant to their own subjects, but were not connected to any course context at the departments. The students were then asked to write down and submit their responses to the assignments (max. 2 pages) and were given group feedback. The IL part of the course also included a multiple choice test with 20 random questions. It was also possible for the students to attend a session in a computer class where a librarian provided face-to-face feedback and information search training. Only in a few cases were the students given personal feedback. Group feedback worked well, but the assessment was not an easy task when you do not meet the student in real life.

When evaluating the ASF course, the students had very divided opinions. Some of the students had no experience of learning platforms as Moodle and found it, and the assignments, confusing and fuzzy, whereas others thought the idea of gathering course material and other relevant information in one place was very practical. The test was appreciated by many, but considered as not pedagogical by some. When the teachers and the librarians involved evaluated the course, they thought the small groups created good contacts, but concluded that there were too many assignments. Too many assignments create administrative problems and drop-outs. The IL tests and assignments, though, worked well. The assignments could, however, be more problem-based, and the IL training in computer classes should ideally be mandatory, since only a part of the students met with the librarians face-to-face. To conclude: the IL part of the course was still quite traditional although it was a step forward to integrate it within the larger ASF course. Since the library has years of experience of teaching online courses, the IL part of the ASF course received more positive feedback than the other modules. When planning ahead for the future, the comparison between the traditional or semi-integrated courses with the embedded course for Chemical engineering students should be taken into consideration.

The IL part of the ASF course at the Faculty of Social Sciences, Business and Economics and the Faculty of Science and Engineering (except Chemical engineering) followed more or less the same structure as the ASF course at the Faculty of Arts, Psychology and Theology. The embedded approach is described below.

\subsection{Academic study skills in Chemical Engineering}

An engineer is often required to find information about raw materials, processes or the product, i.e. information retrieval is often very concrete and related to a specific context. The students in the Chemical Engineering programme also prefer to work with "hands-on" projects involving practical, tangible tasks in opposite to other disciplines were self-evaluation and reflection are favoured. The course "Academic skills for Chemical Engineering" has therefore been planned around a group-work about a well-known, commercially available product, where the training in academic skills is fully embedded.

In the beginning of the course, the teachers divided the students into groups. This promoted mixing and avoided groups of students that already knew each other. The group members also had different roles (as chairperson, secretary and writers), which ambulated during the course. This made it difficult for indolent students to take advantage of more productive group members.

Each group was assigned a product, e.g. lactose-free milk, sugar-free energy drink, car tyres, glue, etc. The course programme was divided into themes, were the students were supposed to exploit different aspects of their product. The themes included raw materials, production steps, 
dimension and process control, distribution, and life cycle analysis. Each of these themes focused on a specific aspect of the product or its production, as well as on developing academic skills.

The examination of the course included several quizzes in the teaching platform, an oral group presentation, a poster, and a report that was updated throughout the course with new product information from the different themes. The report was written as a thesis with a predefined layout, including lists of content and references, as well as cross-references in the text and to all figures. It is recommended that the students in Chemical Engineering use the Harvard system, at least up to the BSc thesis, so this was an excellent opportunity for the students to become acquainted with this reference system.

The IL part of the course was introduced during a lecture in a computer class. After the session, the students continued to search for information about their product and used the information in their report. They were also asked to hand in a list of search terms and phrases, as well as a list of references of at least five different types, e.g. book, journal, patent, encyclopaedia, website, thesis, and authority information. The information specialist evaluated the search terms and the references in the report and gave feedback and advice to all students. It was clear that the students made good use of the counselling and used it in the next theme and for their updated reports.

The information specialist was not involved in the later parts of the course, but the other teachers could see that the reports were greatly improved during the course, both regarding the content and the references used. The most used reference type in the final report was websites (Figure 1),since the projects were about commercial products and many of the websites they used contained product or company specific information. It was, though, gratifying to find that $28 \%$ of the references were of very high scientific standard, i.e. patents, scientific journals, university theses and reports, and scientific books.

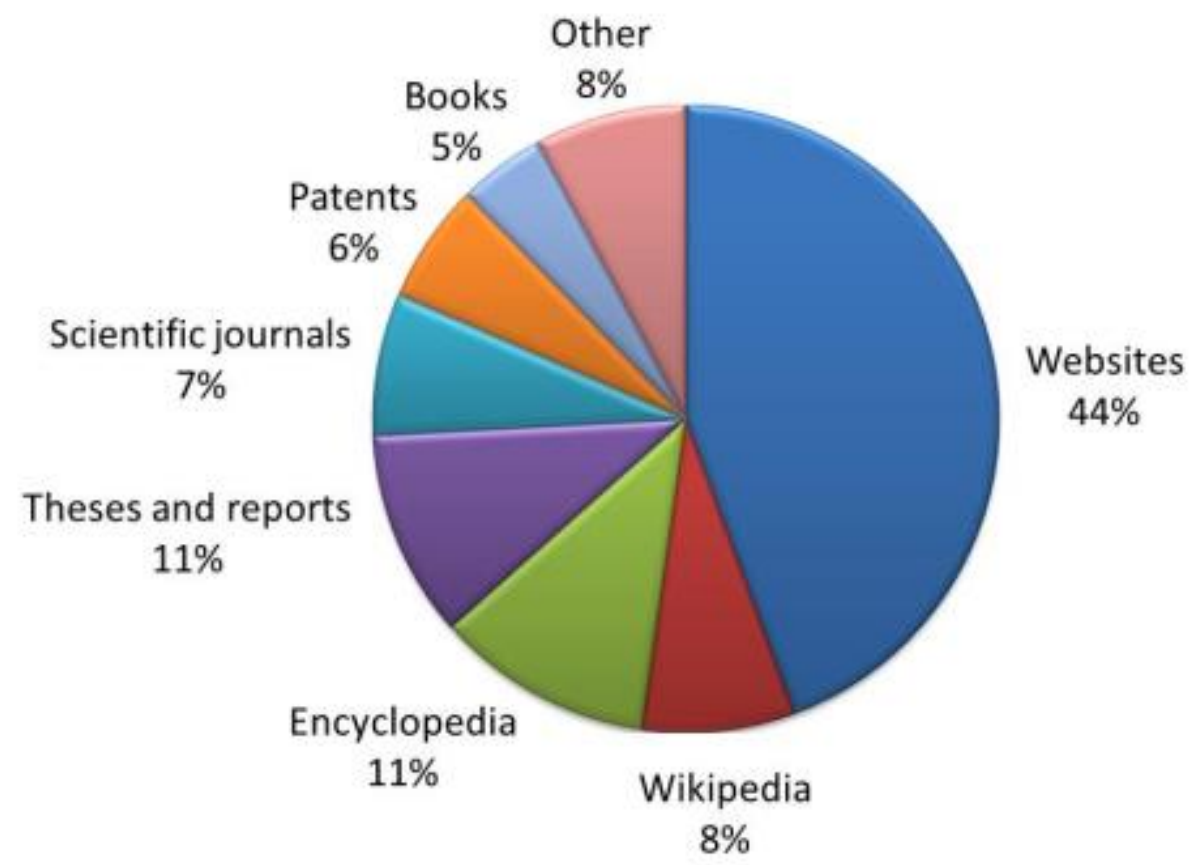

Figure 1. Distribution of reference types used in the final reports. The category "Other" includes newspapers, magazines and information from different authorities such as municipalities, government, EU and the UN. 
The students were asked to evaluate the ASF course, both as a group and individually. One of the questions asked was "what did you learn in this course?". The feedback from the students included several positive comments about the IL part:

- We learned to be meticulous when referring

- We learned how to write an academic text with references according to the Harvard system

- We learned how to search for relevant, "good" material

- We learned how to use our universities e-resources for information retrieval

All students registered to the ASF course for Chemical Engineering 2015 also passed the course, which was quite unique. Another positive outcome of the work done in this course was that it bred a good spirit among the students in the class, which still follows them. Even if this course was targeted to Engineering students, the same idea can be adopted to other disciplines too. The projects do not have to include a commercial product; many other themes are also feasible.

\section{Discussion and conclusion}

The integration of IL studies in ASF courses is evidently motivated since it strengthens the cooperation between the faculty and the library and helps information specialists or librarians gets more involved in the curriculum and the subjects. Taking part in these courses also reveals the differences between the discourses and the learning and teaching methods among the faculties in general, e.g. between the more reflective humanists and the more projectoriented engineers. All of these insights are important to bear in mind when planning IL courses. On the other hand, these experiences suggest that more could be achieved if the Academic study skills course at the Faculty of Arts, Psychology and Theology were to consider one common (or three) projects, and make the IL part of the course more problem-based and contextual. The motivation and learning output considering information search, evaluation of sources and reference management could be enhanced if the students were asked to write a real report or essay already in the first or second semester. The embedded model clearly supports a more constructivist way of learning.

Measuring the effectiveness of IL courses is very difficult. It is also a task with a long time span - the results can probably be seen within a few years, when the results of the students' projects and reports can be compared with earlier students' reports. Obviously, a further study has to be undertaken later on when the references and the literature can be analysed using qualitative methods. 


\section{References}

Costiander-Huldén, E. \& Forslund, T. (2008): Best practice in information skills training. Experiences of web-based courses at Åbo Akademi University. Creating Knowledge V, 20-22.8.2008, Åbo, Finland. Retrieved from http://www.congress.utu.fi/creatingknowledge2008/\#

Elmgren, M., \& Henriksson, A.-M. (2013): Universitetspedagogik. 2. uppl. Lund: Studentlitteratur

Rekommendation för högskolorna i Finland - Informationskompetens i högskolestudierna (2013). Retrieved from: https://www.kamk.fi/loader.aspx?id=816d80da-d9b7-40f8b9fa-9e0be7e14c3f 